\title{
The use of end-tidal carbon dioxide monitoring in patients with hypotension in the emergency department
}

\author{
Cheah P Kheng ${ }^{1}$ and Nik H Rahman ${ }^{2 *}$
}

\begin{abstract}
Background: The aim of this study was to determine the usefulness of end tidal carbon dioxide $\left(\mathrm{ETCO}_{2}\right)$ monitoring in hypotensive shock patients presenting to the ED.

Methods: This was a prospective observational study in a tertiary ED. One hundred three adults in shock with hypotension presenting to the ED were recruited into the study. They were grouped according to different types of shock, hypovolemic, cardiogenic, septic and others. Vital signs and $\mathrm{ETCO}_{2}$ were measured on presentation and at 30-min intervals up to 120 min. Blood gases and serum lactate levels were obtained on arrival. All patients were managed according to standard protocols and treatment regimes. Patient survival up to hospital admission and at 30 days was recorded.

Results: Mean $\mathrm{ETCO}_{2}$ for all patients on arrival was $29.07 \pm 9.96 \mathrm{mmHg}$. Average $\mathrm{ETCO}_{2}$ for patients in hypovolemic, cardiogenic and septic shock was $29.64 \pm 11.49,28.60 \pm 9.87$ and $27.81 \pm 7.39 \mathrm{mmHg}$, respectively. $\mathrm{ETCO}_{2}$ on arrival was positively correlated with systolic and diastolic BP, MAP, bicarbonate, base excess and lactate when analyzed in all shock patients. Early $\mathrm{ETCO}_{2}$ measurements were found to be significantly lower in patients who did not survive to hospital admission $(p=0.005)$. All patients who had $\mathrm{ETCO}_{2} \leq 12 \mathrm{mmHg}$ died in the ED. However, normal $\mathrm{ETCO}_{2}$ does not ensure patient survival.

Conclusion: The use of $\mathrm{ETCO}_{2}$ in the ED has great potential to be used as a method of non-invasive monitoring of patients in shock.
\end{abstract}

Keywords: End-tidal carbon dioxide, Shock, Hypotension, Emergency department

\section{Background}

Shock with hypotension is the main presentation of many diseases to the emergency department (ED). Patients can present with hypovolemic, cardiogenic, anaphylactic, neurogenic or even septicemic shock. The presentation of shock may be obvious as in a patient with the ultimate shock state, cardiac arrest or mildly as in the patient with decompensated cardiac failure. With the evolving treatment and management of shock, the mortality remains high. Emergency physicians and scientists are continuously trying to find new methods to recognize shock at an earlier stage and initiate early treatment [1]. Traditionally, initial therapy of shock in

\footnotetext{
* Correspondence: nhliza@hotmail.com

${ }^{2}$ Department of Emergency Medicine, School of Medical Sciences, USM, Kota Bharu 16150, Malaysia

Full list of author information is available at the end of the article
}

the emergency department concentrates on the normalization of vital signs such as heart rate, mean arterial pressure (MAP) and central venous pressure rather than restoration of adequate tissue oxygenation and perfusion. This concept is not reliable as blood flow cannot be reliably inferred from heart rate and blood pressure measurements until extreme hypotension occurs [2].

Capnography has been used extensively during cardiac arrest situations when there is a need to do CPR. Cardiac arrest diminishes cardiac output and therefore decreases elimination of carbon dioxide $\left(\mathrm{CO}_{2}\right)$ from the lungs. Successful resuscitation will show an increase in end tidal carbon dioxide $\left(\mathrm{ETCO}_{2}\right)$. It has helped as a prognostic tool and has even been suggested to be used as a marker of futility [3]. $\mathrm{ETCO}_{2}$ has been well documented to be reduced in volume-related hypotensive states where the cardiac output is reduced. In this study, 
we would like to investigate the usefulness of this tool in the ED particularly in patients with shock $[4,5]$. We attempted a study to determine the usefulness of $\mathrm{ETCO}_{2}$ in patients with shock who present to the ED. In specific, we would like to determine the correlation between $\mathrm{ETCO}_{2}$ and traditional vital signs and laboratory findings, and to compare early mean $\mathrm{ETCO}_{2}$ with outcome of patients in shock.

\section{Methods}

This prospective observational study was conducted in a regional tertiary referral center with annual patient attendance to ED of approximately 60,000. It is a teaching hospital for undergraduate and residency-based programs with many specialized fields including Emergency Medicine. All patients who presented to the ED from 1 June 2009 to 30 December 2009 with clinical signs of shock managed in the resuscitation zone were enrolled in this study. No randomization was done. Consent was obtained from either the patient or next of kin by signing the consent form (Figure 1).

The study proposal was presented to the department board review and the ethics committee. Approval was obtained from the university research ethics committee (Human) on 16 March 2009,reference no. USMKK/ PPP/JEPeM [200.4(1.7)]. The study was funded by using the short-term grant (1-year duration) provided by the university (grant no. 1001/PPSP/812091). The makers of the equipment used throughout the study had no involvement. The researchers declared no conflict of interest.

Inclusion and exclusion criteria were as follows:

\section{Inclusion criteria:}

(1) Patient aged 18 years old and above on the day of presentation

(2) Be in any kind of shock state managed in the ED

(3) Initial blood pressure below systolic of $90 \mathrm{mmHg}$ or $\mathrm{MAP}<60 \mathrm{mmHg}$.

(4) Able to attach the capnometer probe easily.

\section{Exclusion criteria:}

(1) Patient who arrives to ED in asystole or in a terminal rhythm.

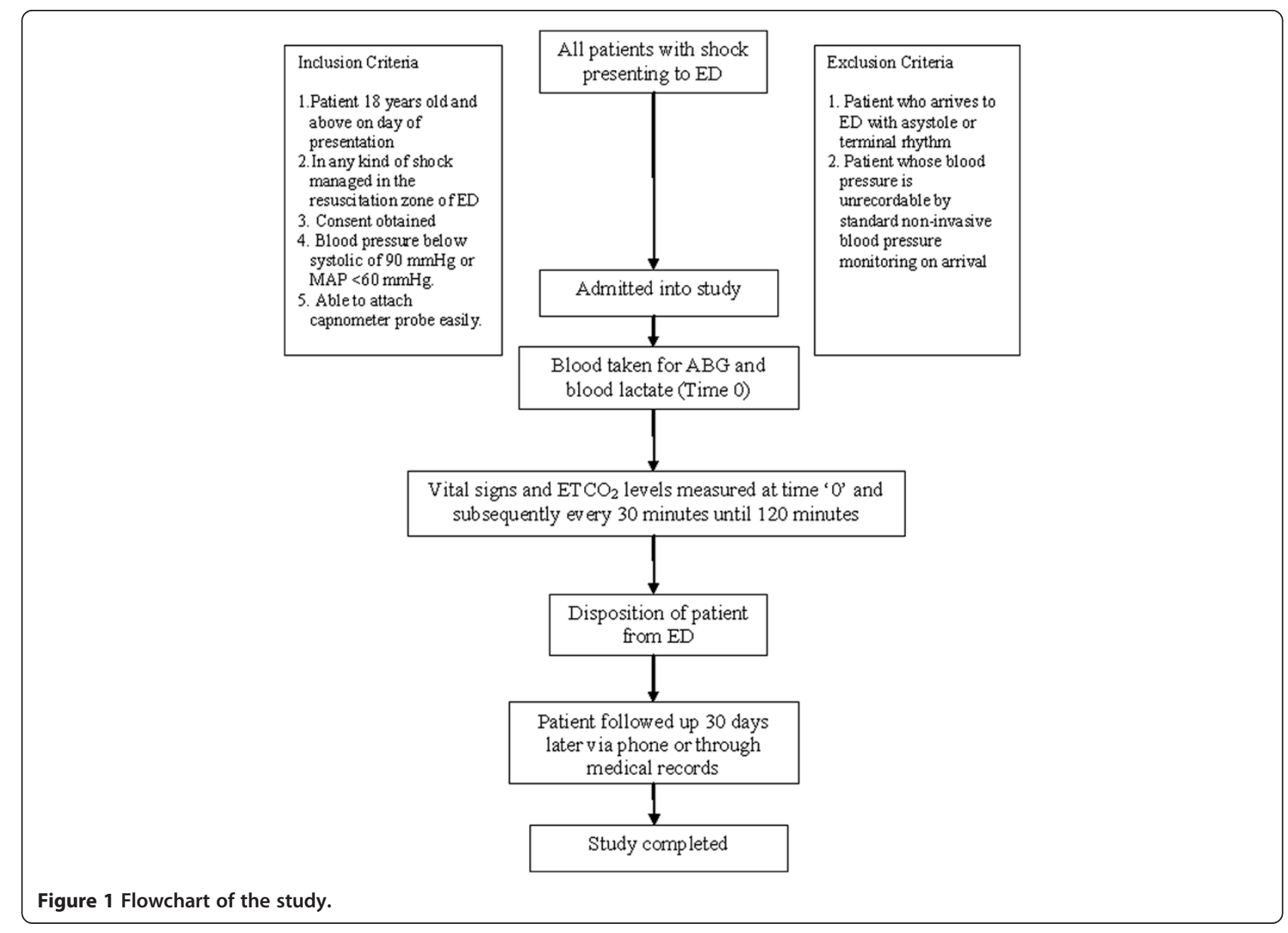


(2) Patient whose blood pressure is unrecordable by standard non-invasive blood pressure monitoring on arrival.

(3) Patients who had received resuscitation in the primary health center prior to transportation to the study center.

(4) Patients who are end-of-life, terminally ill and have advanced directives for do not resuscitate or attempt of active resuscitation.

(5) Elevated $\left[\mathrm{P}\left(\mathrm{a}-\mathrm{ETCO}_{2}\right)\right]$ gradient of more than 6 mmHg suggesting the presence of a complex pulmonary pathology that affects the $\mathrm{ETCO}_{2}$

\section{Sample size calculation \\ To compare means of early $\mathrm{ETCO}_{2}$ with outcome of patients in shock}

Software: PS

Independent $t$-test calculation

Power: $80 \%$

Type 1 error: $5 \%$

Diff: 10

Within SD: 14.7mmHg (Asplin and White, 1995) [6]

Ratio: 3 (alive)/ 1 (dead)

\section{Variables}

Independent variable

\section{(1) $\mathrm{ETCO}_{2}$}

Dependent variables

(1) Blood pressure, MAP, heart rate, respiratory rate, oxygen saturation at time $0,30 \mathrm{~min}, 60 \mathrm{~min}, 90 \mathrm{~min}$ and $120 \mathrm{~min}$ after arrival

(2) Blood lactate, $\mathrm{pH}, \mathrm{P}_{\mathrm{a}} \mathrm{CO}_{2}$, base excess and bicarbonate levels on arrival

(3) Diagnosis and classification to a specific type of shock

(4) Immediate survival to hospital admission

(5) Short-term survival at 30 days

\section{Preparation}

Briefing sessions were given to staff working in the ED. Emergency medicine residents were informed regarding the inclusion and exclusion criteria, data collection procedures and consent, and also familiarized with the data collection sheets. Staff nurses in the ED were trained to use the $\mathrm{ETCO}_{2}$ sampling device for intubated and nonintubated patients. Proper reading procedure was also emphasized for accuracy of reading.

\section{Equipments}

The Datascope ${ }^{\circledR}$ Passport 2 monitoring system, manufactured in the USA, was used for this study. This monitoring device includes noninvasive blood pressure, pulse rate, respiratory rate, $\mathrm{O}_{2}$ saturation and $\mathrm{ETCO}_{2} . \mathrm{ETCO}_{2}$ readings were obtained through the Microstream ${ }^{\circledR}$ $\mathrm{ETCO}_{2}$ technology by using the FilterLine ${ }^{\mathrm{Tm}}$ set line for intubated patients and the CapnoLine ${ }^{\mathrm{TM}}$ sets for nonintubated patients. $\mathrm{ETCO}_{2}$ monitoring for non-intubated spontaneously breathing patients was achieved through the nasal cannula device. Expiratory air from the patient was sampled by the set and streamed to the monitor where the $\mathrm{ETCO}_{2}$ reading and capnograph were displayed. Failure of the tracing to achieve a true plateau can possibly occur under circumstances of inappropriate sampling technique, brief exhalation or heterogeneously distributed ventilation. Nurses were trained to take a reading only when the normal waveform is seen on the monitor. This ensured accuracy of the reading. The $\mathrm{ETCO}_{2}$ function of the machine was calibrated daily according to the manufacturer recommendation.

\section{Data entry}

Data entry was done using the data collection sheet. Data collected include the patient's registration number, sex, age, ethnic group, past medical history and current diagnosis. The most likely type of shock was recorded, and allowance was given to record more than one type of shock depending on patient's presentation.

\section{Data analysis}

All data collected were computed and analyzed using the Statistical Packages for Social Science (SPSS) by SPSS Inc., Chicago Ill., software version 12.0.1, registered to the medical school. Independent $t$-test and Pearson's correlation were used in this study.

\section{Results}

This study was carried out over a period of 7 months, from 1 June 2009 until 30 December 2009. A total of 103 patients were successfully enrolled in this study. Fifty-two percent $(n=54)$ were male patients with mean age for the whole study group of 54 years $(\mathrm{SD} \pm 17.58$ ). We had eliminated nine patients with the $\left[\mathrm{P}\left(\mathrm{a}-\mathrm{ETCO} \mathrm{CO}_{2}\right)\right]$ of more than $6 \mathrm{mmHg}$ from the study as this value indicated patients might have more than one pulmonary pathology, which would affect the accuracy of $\mathrm{ETCO}_{2}$ interpretation. The types of shock presented were hypovolemic shock $(n=37)$, septic shock $(n=34)$ and cardiogenic shock $(n=30)$. Only two cases presented with another type of shock, namely anaphylactic shock. The mean end tidal $\mathrm{CO}_{2}$ on arrival in the department was $29.07 \mathrm{mmHg}(\mathrm{SD} \pm 9.96)$. Endotracheal intubation was carried out in $48 \%(n=49)$ of the studied sample. 
The majority of study participants presented with only one type of shock, with only 13 patients (12.6\%) having a diagnosis of two types of shock on arrival. Of these mixed shock presentations, seven had mixed septic and hypovolemic shock $(n=7)$, and others were mixed cardiogenic and septic shock $(n=6)$. Distribution of the types of shock on presentation was also quite balanced, with a slight majority of patients presenting with hypovolemic shock (35.9\%). However, there were only two patients who presented with shock other than hypovolemic, septic or cardiogenic; hence, they were grouped as others (Figure 2). We found that almost half of the study subjects needed airway intubation in the ED. The comparison of the vital parameters at 0 and $120 \mathrm{~min}$ after arrival in the ED in both sexes is as shown in Table 1. The intubated patients were more likely to die in the ED with a survival rate of just $75.5 \%$ as compared to a $100 \%$ survival of non-intubated patients. The $\mathrm{ETCO}_{2}$ levels between patients who survived to hospital admission and those who died in the ED were significant at zero min $(p=0.005)$. Early measurements of diastolic BP, bicarbonate, base excess and blood lactate also showed a significant difference between immediate and 30-day survivors and non-survivors to hospital admission (Figure 3 and Table 2).

\section{Discussion}

Capnography has been used extensively during cardiac arrest situations when there is a need to do cardiopulmonary resuscitation. Cardiac arrest and shock states diminish cardiac output and therefore decrease elimination of carbon dioxide $\left(\mathrm{CO}_{2}\right)$ from the lungs. Successful resuscitation will show an increase in end tidal carbon dioxide $\left(\mathrm{ETCO}_{2}\right)$. It has helped as a prognostic tool and its use has even been suggested as a marker of futility [7]. Cardiac output is affected by preload, afterload, rate, rhythm, contractility and the presence of shunt. Monitoring of these parameters will be helpful in determining the appropriate intervention to alter cardiac output. An early study in pentobarbitalanesthetized dogs explains the physiologic response of $\mathrm{ETCO}_{2}$ levels. When cardiac output was reduced, $\mathrm{CO}_{2}$ delivery to the lungs decreased, thus causing a reduction of alveolar $\mathrm{PCO}_{2}$ causing part of the decrease in $\mathrm{ETCO}_{2}$. An increase in alveolar dead space causes the remaining reduction in $\mathrm{ETCO}_{2}$. The lower pulmonary perfusion resulting from the decrease in cardiac output dilutes the $\mathrm{CO}_{2}$ in the perfused alveolar spaces, reducing $\mathrm{ETCO}_{2}$ even further. When the reduction of cardiac output was sustained, $\mathrm{CO}_{2}$ accumulation in the peripheral tissues and in venous blood increased and began to restore $\mathrm{CO}_{2}$ delivery to the lung, bringing $\mathrm{ETCO}_{2}$ levels towards baseline.

$\mathrm{ETCO}_{2}$ is used to monitor patients in numerous critically ill conditions. It is traditionally used in intensive care units and operation theatres, and more recently in the pre-hospital care setting and also in the ED. Other investigated indicators that have proved to be promising in the treatment of shock are blood lactate, base deficit, gastric mucosal $\mathrm{pH}$, tissue oxygen concentration and

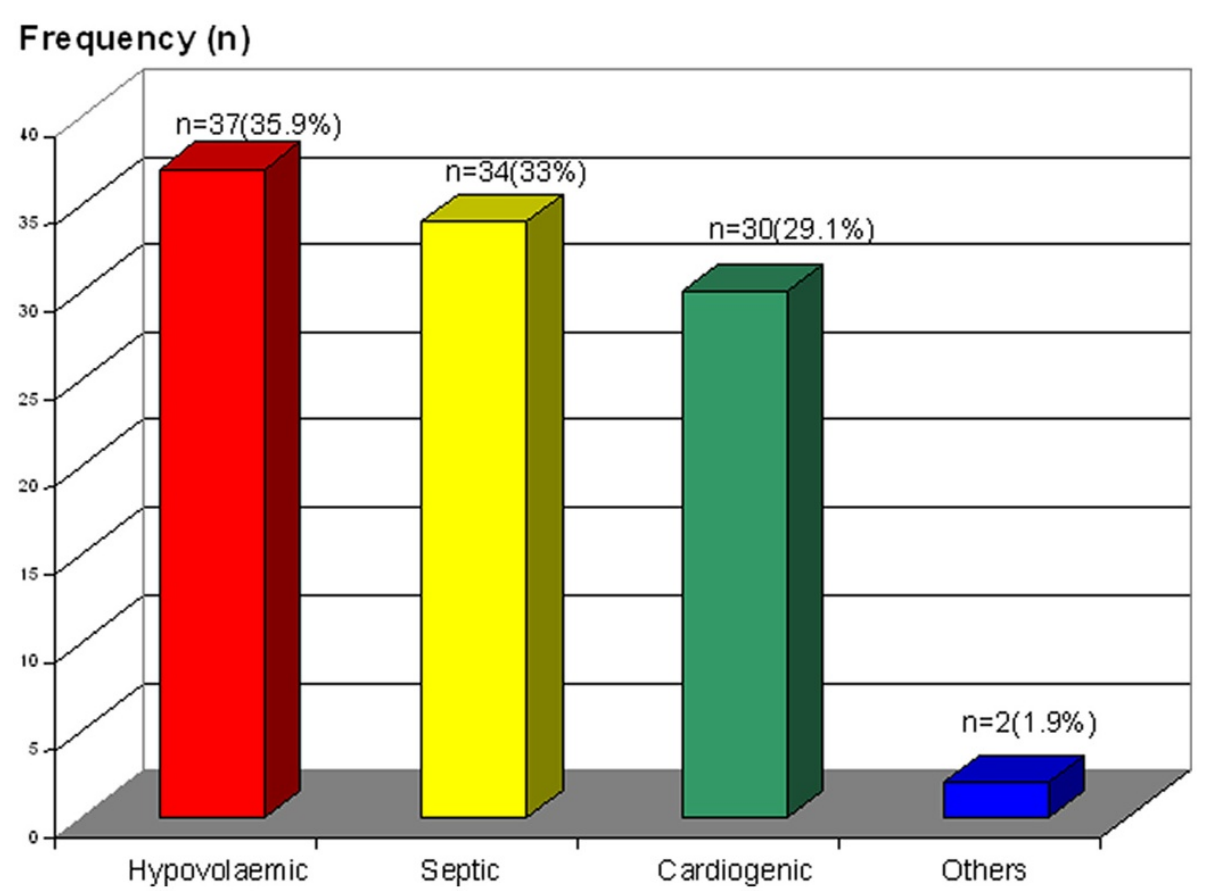

Figure 2 Distribution of type of shock among the study population. 
Table 1 Characteristics of male and female respondents by independent $t$-test

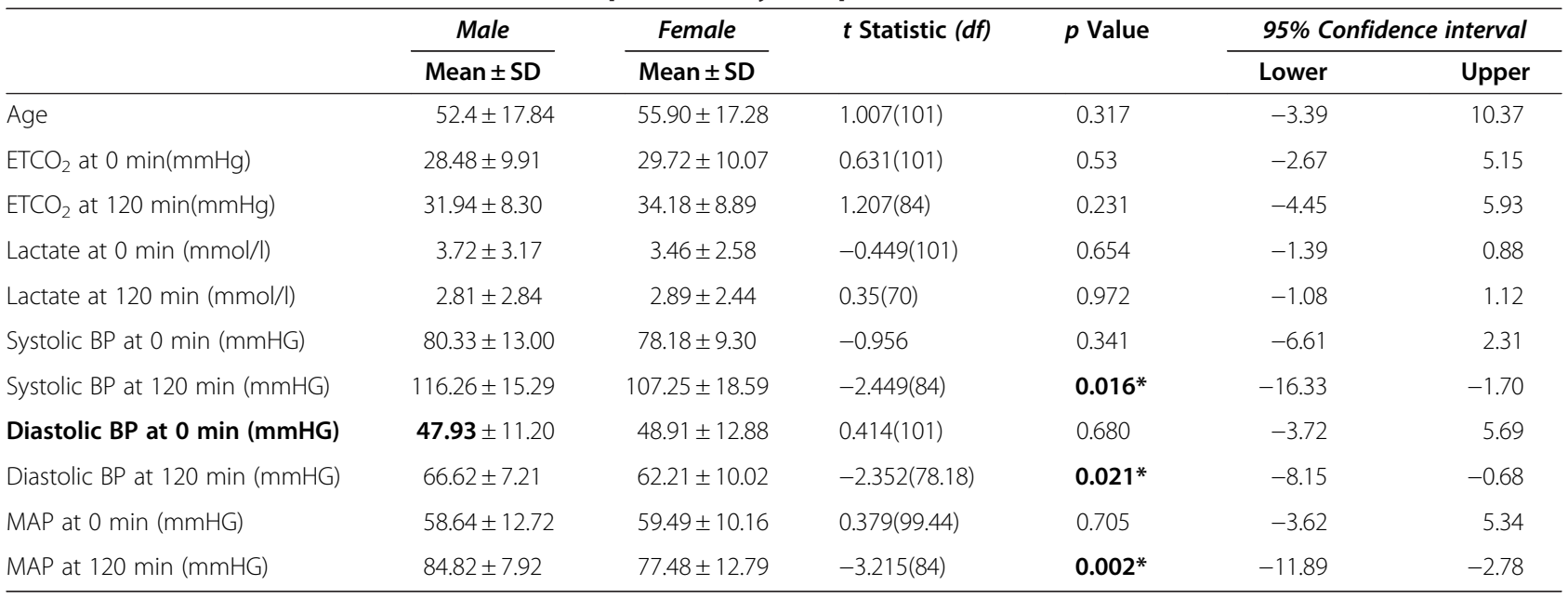

venous hypercarbia. Currently, blood lactate has been shown to have good predictive value of mortality, assessing response to resuscitation and in the assessment of severity. There has also been evidence of $\mathrm{ETCO}_{2}$ being a predictor of high blood lactate levels [8]. The $\mathrm{ETCO}_{2}$ should be able to reflect any systemic hypoperfusion non-invasively and almost immediately. However, as mentioned previously, $\mathrm{ETCO}_{2}$ is affected by cardiac output because cardiac output is the delivery system of $\mathrm{CO}_{2}$ to the lung alveoli. With decreased cardiac output and constant alveolar ventilation, $\mathrm{ETCO}_{2}$ levels would instead be low in situations of low cardiac output but stabilize at a different level if the situation is persistent [9]. This relationship in shock patients is complicated and currently no absolute levels of $\mathrm{ETCO}_{2}$ are available for reference. Exceptions such as pulmonary diseases must be taken into consideration as well as the decrease of cardiac output and pulmonary blood flow,which might alter the $\mathrm{ETCO}_{2}$ concentration.
In our study, average $\mathrm{ETCO}_{2}$ at 0 min was $29.07 \pm 9.96 \mathrm{mmHg}$ (range from 11 to $62 \mathrm{mmHg}$ ). It was noted that $73.8 \%(n=76)$ of patients had an abnormal initial $\mathrm{ETCO}_{2}$ reading of below $35 \mathrm{mmHg}$, which is the lower limit of the normal range. The lowest $\mathrm{ETCO}_{2}$ reading obtained was zero. When investigated further, all patients who had zero as their $\mathrm{ETCO}_{2}$ reading in the data collection sheet had actually died immediately in the ED after the reading was taken. Our finding of low $\mathrm{ETCO}_{2}$ levels in our patient group was not surprising as most of the patients were critically ill. Although there is no study looking at the same type of patient group for comparison, we can perhaps compare almost similar groups. A 2006 Korean paper by Moon and colleagues to determine prognostic factors of hospital survival in patients resuscitated from cardiac arrest in the ED had a patient group almost similarto ours [10].

In early shock, $\mathrm{ETCO}_{2}$ is expected to drop because of the reduction of cardiac output. In our study, non-

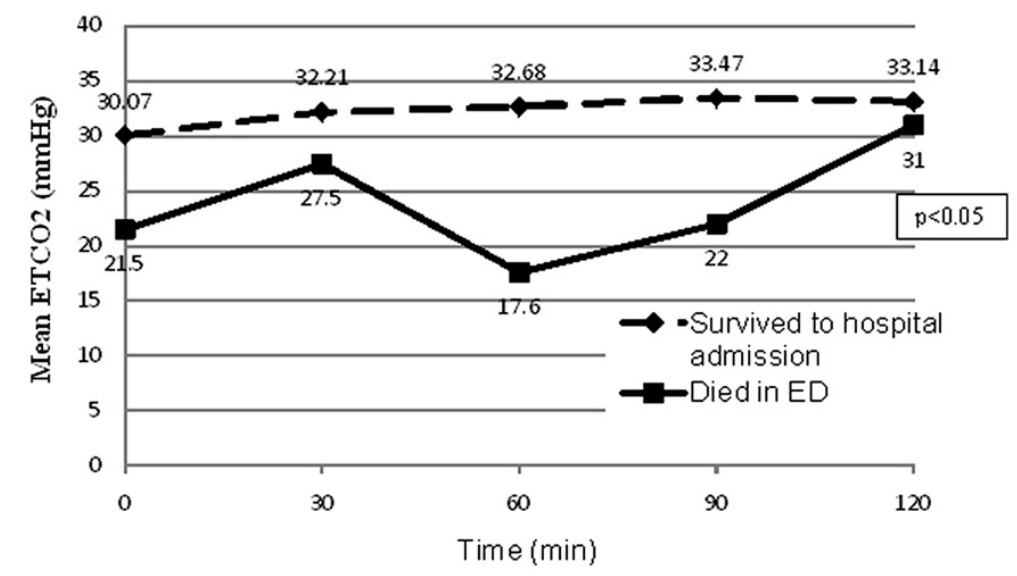

Figure 3 Values of $\mathrm{ETCO}_{2}$ for both early mortality and survival to hospital admission. 
Table 2 Correlation of various parameters with 30-day mortality

\begin{tabular}{|c|c|c|c|c|}
\hline \multirow[t]{2}{*}{ Variables at $0 \mathrm{~min}$} & \multicolumn{2}{|l|}{ Median (interquartile range) } & \multirow[t]{2}{*}{ z Statistic } & \multirow[t]{2}{*}{$p$ Value } \\
\hline & Alive at 30 days $(n=27)$ & Dead at 30 days $(n=25)$ & & \\
\hline Age (years) & $54(34.0)$ & $57(21.5)$ & -1.301 & 0.193 \\
\hline $\mathrm{ETCO}_{2}(\mathrm{mmHg})$ & $32(8.5)$ & $25(18.5)$ & -3.653 & $<0.001$ \\
\hline Systolic BP (mmHg) & $81(16.0)$ & $85(18.5)$ & -1.066 & 0.287 \\
\hline Diastolic BP (mmHg) & $40(22.0)$ & $47(21.5)$ & -0.340 & 0.734 \\
\hline MAP (mmHg) & $62(18.0)$ & $52(23.0)$ & -0.690 & 0.490 \\
\hline Pulse rate (beat/min) & 105(27.0) & $112(34.0)$ & -0.937 & 0.876 \\
\hline Respiratory rate (breaths/min) & $22(12.0)$ & $26(10.0)$ & -0.937 & 0.349 \\
\hline $\mathrm{SpO}_{2}(\%)$ & $100(2.0)$ & $97(10.0)$ & -3.023 & 0.002 \\
\hline $\mathrm{PaCO}_{2}(\mathrm{mmHg})$ & $128(64.9)$ & 117(136.7) & -0.046 & 0.963 \\
\hline Blood pH & 7.45(0.32) & 7.37(0.19) & -0.889 & 0.374 \\
\hline $\mathrm{PaCO}_{2}(\mathrm{mmHg})$ & $30.7(10.0)$ & $30.5(15.7)$ & -0.687 & 0.492 \\
\hline Bicarbonate (mmol/l) & $22.4(6.3)$ & 18.6(8.75) & -2.208 & 0.027 \\
\hline Base excess (mmol/l) & $-3.2(6.4)$ & $-9.5(10.0)$ & -2.593 & 0.010 \\
\hline Blood lactate (mmol/l) & $1.3(1.2)$ & $3.3(5.1)$ & -4.778 & $<0.001$ \\
\hline
\end{tabular}

Mann-Whitney U test.

survivors to hospital admission had significantly lower mean $\mathrm{ETCO}_{2}$ than survivors at o min. In another study, Domsky and co-workers reported that in a group of 100 critically ill patients in surgery in the emergency operating theatre, the mortality rate for an $\mathrm{ETCO}_{2} \leq 28 \mathrm{mmHg}$ was $55 \%$ compared to a lower mortality of $17 \%$ if the $\mathrm{ETCO}_{2}$ was $>28 \mathrm{mmHg}$. Their overall mortality rate in those trauma patients was $41 \%$ [11]. Although none of the above studies was performed in a similar group of patients, they do support that $\mathrm{ETCO}_{2}$ provides some reflection of the cardiac output and cardiac function in patients that are critically ill and can be used as a prognostic tool. A further observation from our study was that if a patient had an $\mathrm{ETCO}_{2} \leq 12 \mathrm{mmHg}$ at any time during the first $120 \mathrm{~min}$ of arrival to the ED, the patient would not survive to hospital admission. Studies in the late 1980s already established that $\mathrm{ETCO}_{2}$ levels below $10 \mathrm{mmHg}$ are incompatible with life $[12,13]$. In a particular study in 1995 done in the pre-hospital setting, patients in PEA (pulseless electrical activity) were found to have an average $\mathrm{ETCO}_{2}$ of $3.9 \pm 2.8 \mathrm{mmHg}$ after 20 min of unsuccessful CPR. Although there is an indication that a low $\mathrm{ETCO}_{2}$ indicates a grave outcome in the $\mathrm{ED}$, it does not give comfort and reassurance when it is normal $[14,15]$.

\section{Limitations}

In this study, we selected all patients in shock that satisfy the criteria of hypotension. We knew that patients in shock might not have hypotension at the outset but may develop hypotension later. By using hypotension as criteria, we have eliminated quite a number of patients in shock, and our results might not be representative of all patients in shock. However, this would not defeat the purpose of the study,which was to use $\mathrm{ETCO}_{2}$ for the monitoring of patients in shock with the presence of hypotension. Issues regarding $\mathrm{ETCO}_{2}$ monitoring include the two types of monitoring device available. One is the nasal cannula for spontaneously breathing patients, and the other is attached to the ETT for intubated patients. In intubated patients, getting a proper capnogram on the monitor is usually easy, but the same cannot be said for the nasal cannula. Staff in the ED needs to be well trained to attach the cannula properly and view the proper capnogram before taking a reading in order for the $\mathrm{ETCO}_{2}$ measurement to be accurate. The time of intubation and the complications of an advanced airway were not taken into consideration in this study. Complications such as aspiration, one lung ventilation and a pneumothorax caused by intubation will affect the respiratory system and might cause respiratory failure on top of the initial diagnosis on presentation. For example, instead of a single pathology such as hypovolemic shock from an intra-abdominal injury, the patient now has two pathologies, one caused by the intubation procedure. In these cases, calculating the $\mathrm{PaCO}_{2}$ and $\mathrm{ETCO}_{2}$ gradient $\left[\mathrm{P}\left(\mathrm{a}-\mathrm{ETCO}_{2}\right)\right]$ might be useful as an indicator of dead space ventilation and the changes in airway physiology.

\section{Conclusion}

The monitoring of $\mathrm{ETCO}_{2}$ in ED is a useful non-invasive way to gain extra information about the patient in shock. It may also be able to guide us in making decisions 
regarding resuscitation and futility. However, the interpretation of $\mathrm{ETCO}_{2}$ in critically ill patients must be done with caution, and many other factors may affect the reading. $\mathrm{ETCO}_{2}$ has great potential in the field of critical care and emergency medicine as a method of noninvasive monitoring.

\section{Competing interests}

The authors declare that they have no competing interest.

\section{Authors' contributions}

NHR: Proposal of study, statistics, manuscript preparation. CPK: Methodology, patient recruitment, writing up results, tabulation. All authors read and approved the final manuscript.

\section{Acknowledgement}

Thank you to all emergency medicine residents and nursing staff of the Department of Emergency Medicine at the Hospital University Sains Malaysia who assisted the researchers in gathering the data.

Thanks also to the director of the hospital who approved the use of patient data from the hospital records.

\section{Author details}

'Department of Emergency \& Trauma, Hospital Queen Elizabeth, Kota Kinabalu, Sabah, Malaysia. ${ }^{2}$ Department of Emergency Medicine, School of Medical Sciences, USM, Kota Bharu 16150, Malaysia.

Received: 28 November 2011 Accepted: 23 June 2012

Published: 24 July 2012

\section{References}

1. Emanuel RM, PR, Bryant Nquyenn H: A Comprehensive Study Guide. In Emergency Medicine. Edited by Tintinalli JE KG, Stapczynski JS. New York: McGraw-Hill, Inc; 2004.

2. Wo CC, Shoemaker WC, Appel PL, Bishop MH, Kram HB, Hardin E: Unreliability of blood pressure and heart rate to evaluate cardiac output in emergency resuscitation and critical illness. Crit Care Med 1993, 21(2):218-223.

3. Sanders AB: Capnometry in emergency medicine. Ann Emerg Med 1989, 18(12):1287-1290.

4. Courtney DM, Watts JA, Kline JA: End tidal CO(2) is reduced during hypotension and cardiac arrest in a rat model of massive pulmonary embolism. Resuscitation 2002, 53(1):83-91.

5. Hemnes AR, Newman AL, Rosenbaum B, Barrett TW, Zhou C, Rice TW, Newman JH: Bedside end tidal $\mathrm{CO} 2$ as a screening tool to exclude pulmonary embolism. EurRespir J 2009.

6. Asplin BR, White RD: Prognostic value of end-tidal carbon dioxide pressures during out-of-hospital cardiac arrest. Ann Emerg Med 1995, 25(6):756-761.

7. Sanders AB, Kern KB, Otto CW, Milander MM, Ewy GA: End-tidal carbon dioxide monitoring during cardiopulmonary resuscitation. A prognostic indicator for survival. JAMA 1989, 262(10):1347-1351.

8. McGillicuddy DC, Tang A, Cataldo L, Gusev J, Shapiro NI: Evaluation of endtidal carbon dioxide role in predicting elevated SOFA scores and lactic acidosis. Intern Emerg Med 2009, 4(1):41-44.

9. Isserles SA, Breen PH: Can changes in end-tidal PCO2 measure changes in cardiac output? AnesthAnalg 1991, 73(6):808-814.

10. Moon SW, Lee SW, Choi SH, Hong YS, Kim SJ, Kim NH: Arterial minus endtidal $\mathrm{CO} 2$ as a prognostic factor of hospital survival in patients resuscitated from cardiac arrest. Resuscitation 2007, 72(2):219-225.

11. Domsky M, Wilson RF, Heins J: Intraoperative end-tidal carbon dioxide values and derived calculations correlated with outcome: prognosis and capnography. Crit Care Med 1995, 23(9):1497-1503.

12. Falk JL, Rackow EC, Weil MH: End-tidal carbon dioxide concentration during cardiopulmonary resuscitation. $N$ Engl I Med 1988 318(10):607-611.

13. Gazmuri R, Kube E: Capnography during cardiac resuscitation: a clue on mechanisms and a guide to interventions. Crit Care 2003, 7(6):411-412.
14. Wayne MA, Levine RL, Miller CC: Use of end-tidal carbon dioxide to predict outcome in prehospital cardiac arrest. Ann Emerg Med 1995, 25(6):762-767.

15. Weil MH, Bisera J, Trevino RP, Rackow EC: Cardiac output and end-tidal carbon dioxide. Crit Care Med 1985, 13(11):907-909.

doi:10.1186/1865-1380-5-31

Cite this article as: Kheng and Rahman: The use of end-tidal carbon dioxide monitoring in patients with hypotension in the emergency department. International Journal of Emergency Medicine 2012 5:31.

\section{Submit your manuscript to a SpringerOpen ${ }^{\circ}$ journal and benefit from:}

- Convenient online submission

- Rigorous peer review

- Immediate publication on acceptance

- Open access: articles freely available online

- High visibility within the field

- Retaining the copyright to your article

Submit your next manuscript at $\gg$ springeropen.com 